\title{
Hydric Properties Evolution of Spirulina platensis during Drying: Experimental Analysis and Modeling
}

\author{
Eloi Salmwendé Tiendrebeogo ${ }^{1,2,3}{ }^{*}$, Guy Christian Tubreoumya1 ${ }^{1}$ A. O. Dissa ${ }^{1}$, A. Compaoré1, \\ Jean Koulidiati' ${ }^{1}$ F. Cherblanc ${ }^{2}$, J.-C. Bénet ${ }^{2}$, I. Youm ${ }^{3}$ \\ ${ }^{1}$ Laboratoire de Physique et de Chimie de L'environnement (LPCE), Université Ouaga 1 Pr Joseph Ki-Zerbo, Ouagadougou, \\ Burkina Faso \\ ${ }^{2}$ Laboratoire de Mécanique et Génie Civil (LMGC), CNRS, Université de Montpellier 2, Montpellier, France \\ ${ }^{3}$ Centre de Recherche sur les Energies Renouvelables (CERER), Université Cheick Anta Diop, Dakar, Sénégal \\ Email: *tiendrebeogoeloi@yahoo.fr
}

How to cite this paper: Tiendrebeogo, E.S., Tubreoumya, G.C., Dissa, A.O., Compaoré, A., Koulidiati, J., Cherblanc, F., Bénet, J.-C. and Youm, I. (2019) Hydric Properties Evolution of Spirulina platensis during Drying: Experimental Analysis and Modelin. Food and Nutrition Sciences, 10, 516-577.

https://doi.org/10.4236/fns.2019.106041

Received: March 26, 2019

Accepted: June 8, 2019

Published: June 11, 2019

Copyright (๑) 2019 by author(s) and Scientific Research Publishing Inc. This work is licensed under the Creative Commons Attribution International License (CC BY 4.0).

http://creativecommons.org/licenses/by/4.0/

\section{c) (i) Open Access}

\begin{abstract}
Hydric properties evolution during drying differs from one product to another and has been the subject of various studies due to its crucial importance in modeling the drying process. The variation of these parameters in the solid matrix and in time during the drying of Spirulina platensis has not known an advanced understanding. The objective of this study was to evaluate the evolution of the water content profile, the mass flow, the concentration gradient and the diffusion coefficient during the drying of Spirulina platensis taking into account the shrinkage. Modeling and experimental analysis (at $50^{\circ} \mathrm{C}$ and $\mathrm{HR}=6 \%$ ) by the cutting method a cylinder $20 \mathrm{~mm}$ in diameter and $40 \mathrm{~mm}$ thick were carried. The water content profiles of two different products grown in semi-industrial farms from Burkina Faso and France with initial water contents respectively of the range from $2.73 \mathrm{~kg}_{\mathrm{w}} / \mathrm{kg}_{\mathrm{db}}$ and 3.12 $\mathrm{kg}_{\mathrm{w}} / \mathrm{kg}_{\mathrm{db}}$ were determined. These profiles have been adjusted by a polynomial function. Identical water behavior is observed regardless of the origin of the samples. Water distribution is heterogeneous. Mass flow and concentration gradient are greater at the edge than inside the product. The water transport coefficient, ranging from $1.70 \times 10^{-10}$ to $94 \times 10^{-10} \mathrm{~m}^{2} / \mathrm{s}$, is determined from a linear approach.
\end{abstract}

\section{Keywords}

Drying, Experiment, Modeling, Spirulina platensis, Hydric Property 


\section{Introduction}

In many countries of sub-Saharan Africa, food imports absorbe for a large proportion of national income. For example, in Burkina Faso, per capita food production is now lower than it was 40 years ago. Post-harvest losses related to the degradation of agro-food products contribute to the decline in agricultural productivity. Spirulina platensis, a nutritional and therapeutic seaweed, is used today for complementary food requirements [1] [2] [3]. Cultivated all over the world under several techniques, it is highly porous and deteriorates rapidly in the presence of water. Methods have been proposed in previous studies to produce healthy and nutritious foods, reduce losses associated with the development of severe microorganisms and improve their quality [4] [5] [6] [7].

Drying can make a significant contribution to sustainable agricultural development and improved food security by reducing post-harvest losses and improving the shape of dried produce and their nutritional quality. This process, which aims to strengthen the bonds of water molecules by reducing the latter, is one of the most used techniques to protect the product from degrading agents and to extend its conservation. In addition to stresses and cracks, the drying process often induces water density gradients in the solid matrix. The distribution of water in the solid matrix during drying differs from one product to another. Water is often trapped inside the structure by a crusting phenomenon that accelerates the product degradation. The hydrics properties evolution during drying differs from one product to another and has been the subject of various studies because of its crucial importance in the modeling of the drying process [8]-[13]. Some food products such as the Spirulina platensis continue to be victim mechanicals and biologicals stress.

The diffusion of water in Spirulina platensis had already been approached experimentally by Desmorieux and Dissa [14] [15] in thin layer. This method does not allow to take into account the contribution of the internal phenomena and neglects the influence of the product shrinkage. The complexity of material shrinkage has led some authors [16]-[24] to develop numerical methods in support of experimental data to predict the withdrawal of food products such as potato, okra, banana, Spirulina, cereals, onion etc. The results they have obtained show that the influence of the solid contraction on the transport of water is negligible. These earlier studies are generally carried out under very simplifying assumptions that lead to limited results. The variation of the hydric characteristic parameters in the solid matrix and in time during the drying of the Spirulina platensis has not known an advanced understanding. In this article, the overall objective is to evaluate the evolution of the hydric characteristic parameters of the Spirulina platensis.

The present study is divided into three parts. First, we will determine experimentally the water content profiles of the Spirulina platensis. Then we will evaluate the evolution of the mass flow and concentration gradient and establish a relationship between them. Finally, we will estimate the transport coefficient. 


\section{Method and Materials}

\subsection{Origin, Materials Pretreatment}

The materials used in this study are Spirulina platensis samples from two farm sites located in two different areas:

- "Loumbila" farm situated at $15 \mathrm{~km}$ in the north of Ouagadougou, Burkina Faso. This material sample will be named sample-B,

- "La Fon del Cardaire" farm situated at Gignac in the south of France. This material will be named sample-F.

Their mode of production is not different from one farm to another, from one country to another. These are the methods that change, adapted to the size of the farm, the workforce and the materials available on site. Indeed, the "sample-B" is grown in open ponds and the "sample-F" in glass ponds. However, if these two products were grown in localities with different climates, their seeding is done by strains of the same type "platensis" in basins whose salinity and alkalinity are provided by sodium bicarbonate $\left(\mathrm{NaHCO}_{3}\right)$. Pretreatments were carried out on each biomass harvested to remove a good part of the culture water until reaching a given water content. The methods pretreatment used is different from one farm to another depending on the available materials. Thus, the water content of the sample-B is reduced to about $2.73 \mathrm{~kg}_{\mathrm{w}} / \mathrm{kg}_{\mathrm{db}}$ by manual pressing while that of the sample-F is reduced to about $3.12 \mathrm{~kg}_{\mathrm{w}} / \mathrm{kg}_{\mathrm{db}}$ by a spin under the action of vacuum. These water contents obtained after pretreatment are considered as the water contents initial of the samples. The initial characteristic parameters recorded in Table 1 have been determined using standard methods. The volume of a substance corresponds to the space occupied by this substance. For measurements, a container of cylindrical shape with known dimensions is previously weighed empty so that its mass can be measured and subtracted from that of the container loaded mass $\mathrm{m}$. It is then in an oven maintained at $70^{\circ} \mathrm{C}$ for 48 hours to determine the anhydrous mass $m_{s}$.

\subsection{Sampling}

First, the filtering of biomass through one or two devices superimposed. In general the first consists of a thin mesh of the order of 300 microns which retains any impurities (lumps, insects, leaves). The second is a filter in nylon is of the

Table 1. Initial characteristics of the materials.

\begin{tabular}{cccc}
\hline Parameters & Symbol and units & sample-B & sample-F \\
\hline Solid apparent density & $\rho_{\mathrm{s}}\left[\mathrm{kg} / \mathrm{m}^{3}\right]$ & 284 & 255 \\
Water apparent density & $\rho_{w}\left[\mathrm{~kg} / \mathrm{m}^{3}\right]$ & 776 & 799 \\
Solid real density & $\rho_{\mathrm{s}}^{*}\left[\mathrm{~kg} / \mathrm{m}^{3}\right]$ & 1270 & 1270 \\
Ratio of real densities & $\alpha[\ldots / \ldots]$ & 0.787 & 0.787 \\
Porosity & $\phi[\ldots / \ldots]$ & 0.776 & 0.799 \\
Water content & $w\left[\mathrm{~kg}_{\mathrm{w}} / \mathrm{kg}_{\mathrm{db}}\right]$ & 2.730 & 3.120 \\
\hline
\end{tabular}


order of $50 \mu \mathrm{m}$. After filtering, fresh Spirulina platensis is processed into test-ready samples. A cylindrical shape commonly used in farms for the drying is proposed (Figure 1). To avoid variability and ensure identical initial conditions between samples, the following design process has been adopted: the fresh biomass is moulded in a cylindrical device of $20 \mathrm{~mm}$ diameter and $40 \mathrm{~mm}$ length composed of a tube and a piston made in Teflon; the cylindrical surface of samples are wrapped with plastic film to prevent adhesion between samples. Both end faces are free to ensure a one-dimensional water transport along sample axis; a sample is kept if its initial mass is $m_{0}=0.013 \pm 0.0006 \mathrm{~kg}$.

It is assumed that these conditions are met and the samples are uniform in the initial state.

To understand experimentally the distribution of water in the product during drying, we chose to follow the variation of the water content in the product by cutting samples. The water content in a sample slice is determined by considering the mass of this slice at a given instant and that of the solid phase according to the following Equation (1):

$$
w=\frac{m(x, t)-m_{s}}{m_{s}}
$$

\subsection{Experimental Device and Procedure}

The experimental setup is constituted of a desiccator where the relative humidity is regulated at $6 \%$ by a potassium hydroxide $\mathrm{KOH}$ solution (Figure 2). The cylindrical samples (Figure 2(a)) are put above the solution (Figure 2(b)) while the desiccator is placed in a thermo-regulated chamber (Memmert UFP 600) where the temperature is maintained at $50^{\circ} \mathrm{C}$. At specific time steps of the drying process, one of the samples is removed from the desiccator and immediately $o x$ introduced in a cutting device to obtain slices of $2 \mathrm{~mm}$ thickness. The water content of each slice is determined by differential weighing after 48 hours drying at $70^{\circ} \mathrm{C}$ for complete dehydration. In order for the desired water content profiles to be characteristic of a given single sample, all the samples should be in the same state at the process beginning. Thus, they are prepared under the same

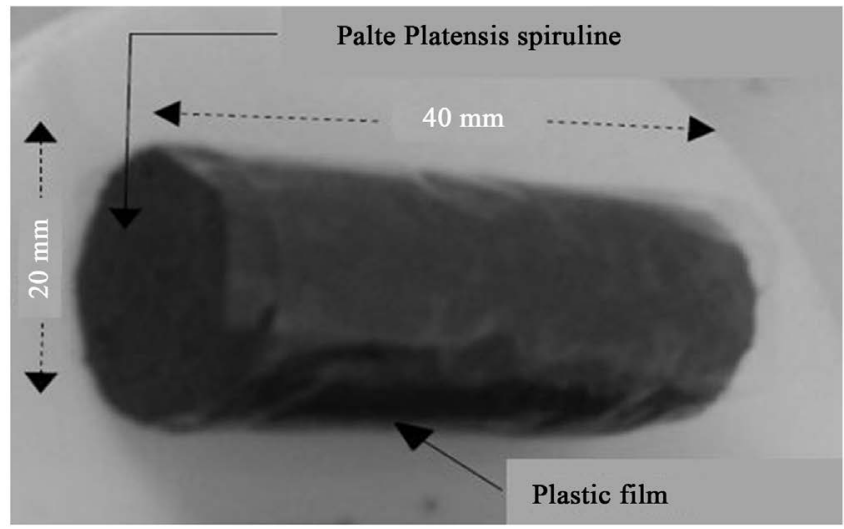

Figure 1. Study sample cylinder. 


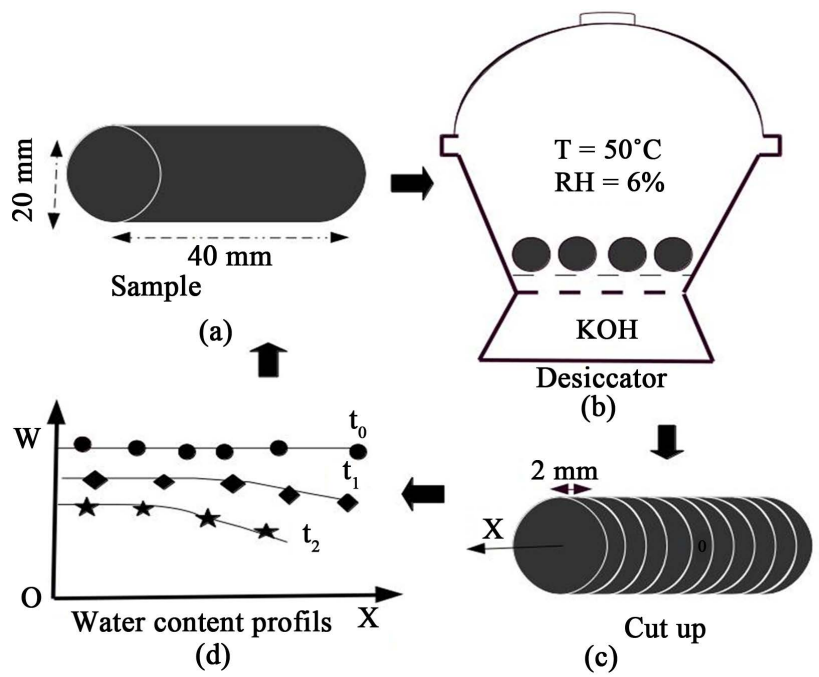

Figure 2. Experimental Principe setup for the characterization of water transport coefficient in Spirulina samples.

conditions as indicated above. The material being symmetrical, the water contents averages of symmetrical points with respect to the median plane are considered. This approach provides to access to the moisture content profiles $w(x, t)$ corresponding to the drying times (Figure $2(\mathrm{~d})$ ). Since we aim to characterize water transport phenomena in a single sample from measurements obtained on various samples, it is essential to have the same initial conditions in all samples. Although special attention is paid to sample preparation, this methodology may have some differences. For this, the experimental water content profiles are approximated by simple polynomial equations (Equation (2)) introducing three parameters $a, b$ and $c$ at each time step.

$$
w(x, t)=a x^{4}+b x^{2}+c
$$

This expression ensures to have a symmetrical evolution with a no flux condition at the symmetry plane. The Experiments are carried out and lasted at most 120 hours ( 5 days). As it for a drying period long the material begins to stiffen and the cutting deviate delicate. For low temperature (less than $25^{\circ} \mathrm{C}$ ), the drying is too slow for reach values with low water content and the range of water content investigated is too narrow. It appears that for longer time period, the material starts to denature and the development of micro-organisms are observed. This could change the process of water transport and should be avoided.

\subsection{Hypothesis and Theoretical Modeling}

Simplifying assumptions are considered to develop the descriptive equations of water transport: the material is assumed to remain diphasic along the experiment, the initial water content in the product is homogeneous, both solid and liquid phases are incompressible, water transport is one-dimensional along the cylindrical sample axis $x$.

The real mass densities are determined over intrinsic volume of water and 
solid phases:

$$
\rho_{w}^{*}=\frac{m_{w}}{V_{w}} ; \rho_{s}^{*}=\frac{m_{s}}{V_{s}}
$$

The material being biphasic, the apparent densities are expressed by [25]:

$$
\begin{gathered}
\rho_{w}=\rho_{w}^{*} \frac{w}{\alpha+w} \\
\rho_{s}=\rho_{s}^{*} \frac{1}{\alpha+w}
\end{gathered}
$$

$\alpha=\rho_{w}^{*} / \rho_{s}^{*}$ is the ratio of real densities. Considering $u_{w}$ and $u_{s}$ as the water and solid phase velocities along $x$, mass balance equations are written [26] [27]:

$$
\begin{aligned}
& \frac{\partial \rho_{w}}{\partial t}+\frac{\partial \rho_{w} u_{w}}{\partial x}=0 \\
& \frac{\partial \rho_{s}}{\partial t}+\frac{\partial \rho_{s} u_{s}}{\partial x}=0
\end{aligned}
$$

The mass flow of water with respect to the solid phase is written as follows:

$$
F_{w}=\rho_{w}\left(u_{w}-u_{s}\right)=\rho_{w} u_{w}-w \rho_{s} u_{s}
$$

For reasons of symmetry, $u_{w}(0, t)=u_{s}(0, t)=0$ and from balance Equations (6)-(7), we obtain by integration the Equations (9) and (10):

$$
\begin{gathered}
\rho_{w} u_{w}(x, t)-\rho_{w} u_{w}(0, t)=\rho_{w} u_{w}(x, t)=-\int_{0}^{x} \frac{\partial \rho_{w}}{\partial t} \mathrm{~d} x \\
\rho_{s} u_{s}(x, t)-\rho_{s} u_{s}(0, t)=\rho_{s} u_{s}(x, t)=-\int_{0}^{x} \frac{\partial \rho_{s}}{\partial t} \mathrm{~d} x
\end{gathered}
$$

By replacing the expressions 9 and 10 in Equation (8) and considering the Equations (8) and (9), the relation of the water flow becomes:

$$
F_{w}=\rho_{w}^{*}\left(w \int_{0}^{x} \frac{\partial}{\partial t} \frac{1}{\alpha+w} \mathrm{~d} x-\int_{0}^{x} \frac{\partial}{\partial t} \frac{w}{\alpha+w} \mathrm{~d} x\right)
$$

Deriving the Equation (4), the density gradient of the water is written:

$$
G_{w}=\rho_{w}^{*} \frac{\partial}{\partial x}\left(\frac{w}{\alpha+w}\right)
$$

Fick's law (Equation (13)) is a relationship that links the water flow to the mass concentration gradient through a phenomenological coefficient [28].

$$
F_{w}=-D_{w} \frac{\partial \rho_{w}}{\partial x}
$$

In the case of geometry and boundary conditions used in experiments, radial water transport can be neglected so that water content is considered uniform in a cross-section at abscissa x. From relations 11 and 13, the water transport coefficient is accessed as a function of the water content. 


$$
D_{w}=-\frac{F_{w}}{G_{w}}
$$

The experimental determination of the water transport coefficient from the exploitation of the water content profiles is carried out as follows. For a particular time step $t_{j}$ and a given water content $w_{k}$, the fitting of the associated water content profile (Equation (2)) can be inverted to give the corresponding abscissa $x_{i}$. Knowing this abscissa, the values of the water flow (Equation (11)) and those of the water density gradient (Equation (12)) can be calculated. In fact, in Figure $2(d)$, the horizontal line associated with the given water content $w_{k}$ can cut several water content profiles providing a set of values $\left(x_{i}, t_{i}\right)$ leading to a set of couples $\left\{F_{w}\left(x_{i}, t_{j}\right), G_{w}\left(x_{i}, t_{j}\right)\right\}$. This set of couples is associated with a single value of the moisture content $w_{k}$ and must correspond to a single value of the coefficient of transport $G_{w}$. In this way, by scrolling through a range of water content values between $0.7<w_{k}<2.5$, this approach makes it possible to determine the evolution of the transport coefficient $D_{w}(w)$ as a function of the water content. The precision on the determination of the experimental results is estimated by statistical parameters: the coefficient $R^{2}$ (Equation (15)): and the root mean square error (RMSE) (Equation (16)): the RMSE squared error and the coefficient (Equation (16)).

$$
\begin{gathered}
R^{2}=1-\frac{\sum_{z=1}^{N}\left(Y_{\text {exp }, \mathrm{z}}-Y_{p r e, z}\right)^{2}}{\sum_{z=1}^{N}\left(\bar{Y}_{\text {exp }, \mathrm{z}}-Y_{p r e, z}\right)^{2}} \\
R M S E=\sqrt{\frac{\sum_{z=1}^{N}\left(Y_{\text {exp }, \mathrm{z}}-Y_{p r e, \mathrm{z}}\right)^{2}}{\sum_{z=1}^{N}\left(\bar{Y}_{\text {exp }, \mathrm{z}}-Y_{p r e, \mathrm{z}}\right)^{2}}}
\end{gathered}
$$

\section{Results and Discussion}

\subsection{Water Content Profiles}

The experimental approach presented above made it possible to obtain a representative evolution of the water distribution inside of the two Spirulina platensis samples types studied (Figure 3 and Figure 4). These profiles are accurately estimated by a polynomial expression (Equation (2)) whose parametric coefficients at each time $t$ of measurement are recorded in Table 2 and Table 3. Data for both samples were recorded differently. It appears that the recording time has no influence on the evolution of the parameters. This function constitutes a base of the calculation program for the coefficient of transport. The water content profiles (axial and temporal variation of the water content in the product) show that the drying process is more important at the ends than inside of the samples. A heterogeneous water distribution is observed along the cylindrical axis. Ce qui montre que la perte d'eau par évaporation à la surface d'échange n'est pas complètement compensée par le transport interne. Considerable shrinkage of the solid matrix is observed and the thickness of the samples is decreased by about $0.6 \mathrm{~mm}$. Trends similar to that of axial shrinkage 


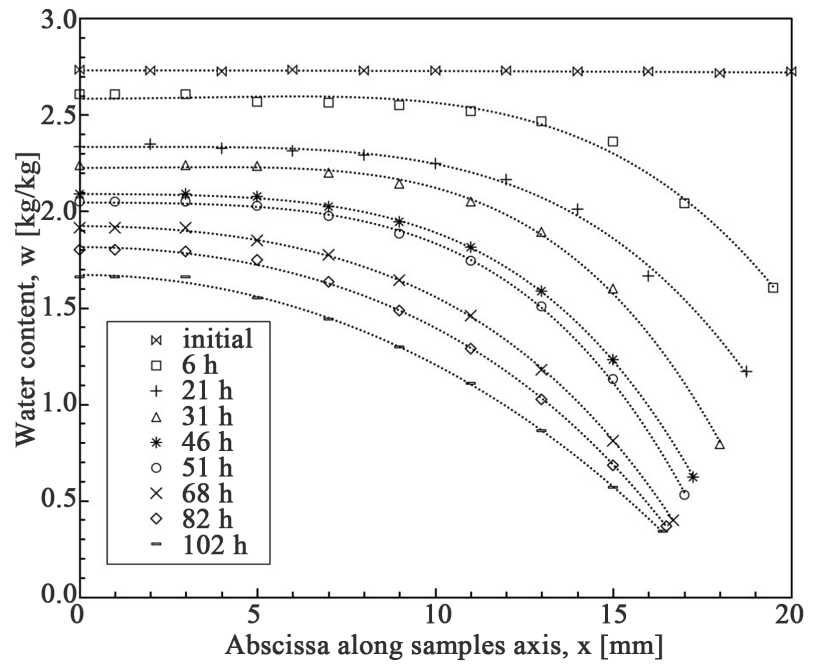

Figure 3. Impact of the thickness on the water content profiles of sample-B at $50^{\circ} \mathrm{C}$.

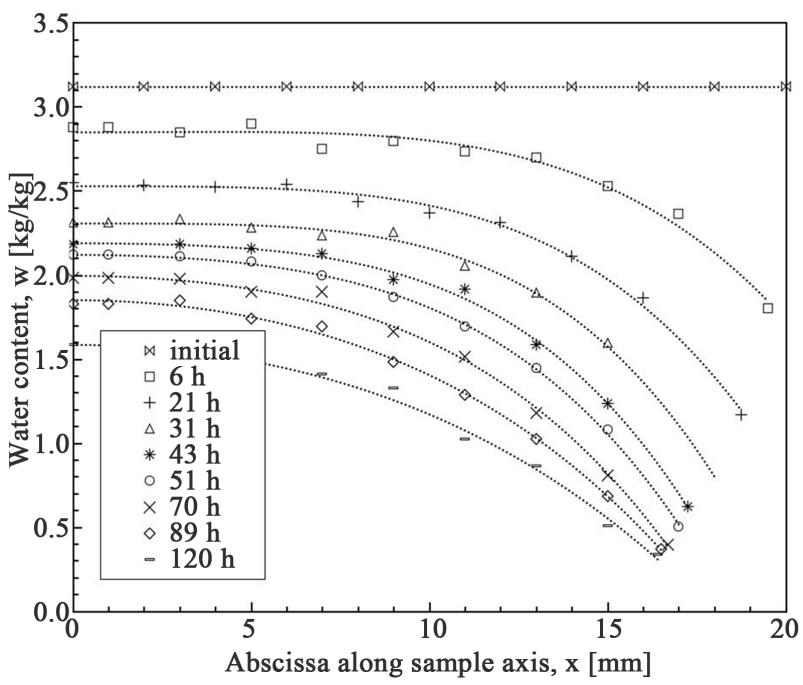

Figure 4. Impact of the thickness on the water content profiles of sample-F at $50^{\circ} \mathrm{C}$.

Table 2. Parameters of the descriptive equation of the sample-B Profiles.

\begin{tabular}{ccccc}
\hline Time & \multicolumn{3}{c}{ Parameters } \\
\hline$t[\mathrm{~h}]$ & $R^{2}$ & $a$ & $b$ & $c$ \\
\hline 0 & 0.989 & 2.733 & -33.826 & 17,144 \\
6 & 0.991 & 2.586 & 625.540 & $-8,407,669$ \\
21 & 0.990 & 2.336 & 101.345 & $-9,839,223$ \\
31 & 0.995 & 2.227 & 463.387 & $-14,987,570$ \\
46 & 0.988 & 2.092 & -513.382 & $-14,835,938$ \\
51 & 0.992 & 2.047 & -487.359 & $-16,330,653$ \\
68 & 0.997 & 1.925 & -2655.867 & $-10,180,982$ \\
82 & 0.986 & 1.876 & -3533.390 & $-6,610,475$ \\
102 & 0.987 & 1.672 & -4476.347 & $-1,830,454$ \\
\hline
\end{tabular}


Table 3. Parameters of the descriptive equation of the sample-F Profiles.

\begin{tabular}{ccccc}
\hline Time & \multicolumn{4}{c}{ Parameters } \\
\hline$t[\mathrm{~h}]$ & $R^{2}$ & $a$ & $b$ & $c$ \\
\hline 0 & 0.992 & 3.120 & -9.595 & 0.249 \\
6 & 0.996 & 2.850 & 277.445 & -7688264.958 \\
21 & 0.996 & 2.830 & -97.477 & -10526006.869 \\
31 & 0.992 & 2.308 & -82.477 & -14114767.017 \\
43 & 0.994 & 2.191 & -988.399 & -14460053.643 \\
51 & 0.991 & 2.122 & -1882.984 & -12724621.226 \\
70 & 0.995 & 1.997 & -2908.400 & -103330487.181 \\
89 & 0.996 & 1.852 & -3885.733 & -5791090.036 \\
120 & 0.997 & 1.586 & -3781.971 & -3583369.902 \\
\hline
\end{tabular}

of the spirulina have been theoretically demonstrated for the alumina gel by Chemkhi (2008) [29]. The profiles make it possible to establish the drying kinetics for various abscissas of $x$ up to a value of the order of $5 \mathrm{~mm}$. These water content profiles will serve as a basis for determining the transport coefficient and its evolution throughout the drying process.

\subsection{Drying Kinetics}

In Figure 5 and Figure 6 are carried the variations water content at various abscissa as a function of time for both types of samples. The results are classic: the surfaces dry faster than the heart of the product. But, the differences between the curves are quite considerable. In fact, the water discharged from the zones close to the surface is not compensated by the water flowing from the heart towards the surface under the effect of the large gradients of the liquid phase, the motor terms of the flow. The study is carried out for abscissa between $5 \mathrm{~mm}$ and 16 $\mathrm{mm}$. Because, out of this interval, the variations of water content and concentration gradient are too small and the experiments could not be exploited.

\subsection{Water Mass Flow and Apparent Concentration Gradient}

From these profiles above, we have represented on the one hand the evolution of the water transport flow and that of density gradient at different thicknesses in the initial configuration of the sample $(x \leq 16 \mathrm{~mm})$ as function of time (Figure $7(a)$ and Figure $7(b))$ and secondly their variation as function of the water content (Figure 7(c) and Figure 7(d)). On the sample-B and sample-F, we note that the transport flow and the gradient have a similar appearance at each abscissa. They increase that the further one moves away from the median plane $(x=0)$. The gradients grow from the drying beginning and decrease towards the process end. For a given abscissa, the water transport flow becomes constant and has some inflection points that reflect the influence of an instantaneous contraction of the material during drying which contributes to migrate the water. 


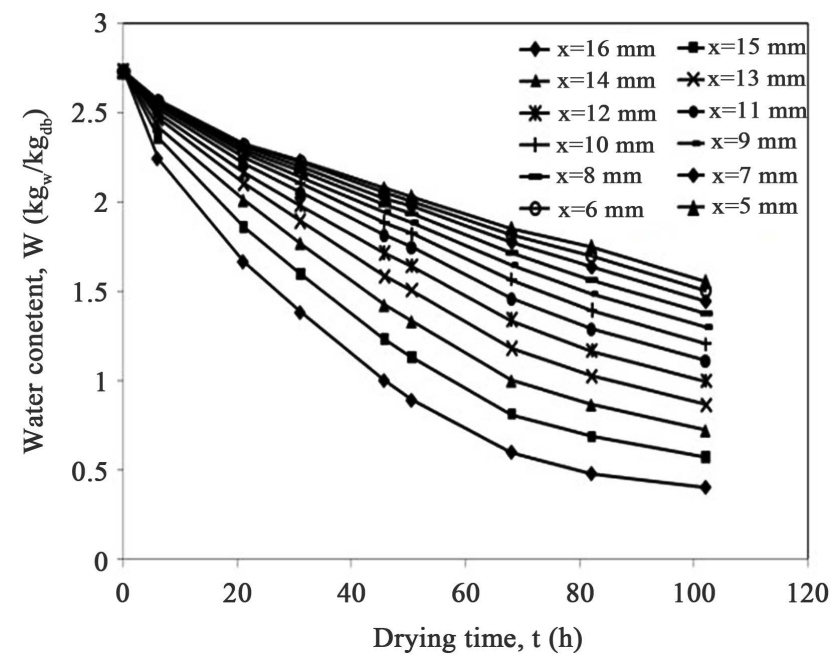

Figure 5. Thickness Influence on the sample-B water content.

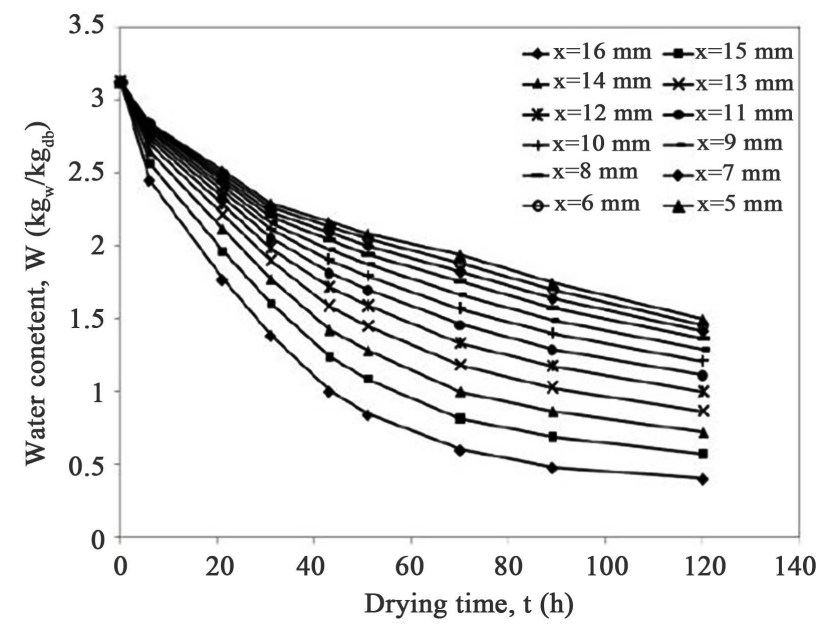

Figure 6. Thickness Influence on the sample-F water content.

Decreasing curves indicate that the flow of water carried by filtration from the interior to the exchange surface is not compensated for in the pores. The main interest of the representation of the gradient as a function of time and as a function of the water content lies in the identification for each slice, a critical period and a critical water content (Figures 8(a)-(d)) to from which the contribution of the solid contraction to the transport of water becomes very negligible. We have just chosen to draw the curves of Figure 7(a), Figure 7(b), Figure 8(a) and Figure 8(b) on abscissa less than $13 \mathrm{~mm}$. Because beyond these values, the rigidity of the products deviates more important and the exploitation of the data becomes delicate.

\subsection{Relation between Water Flux and Concentration Gradient}

In Figure 9 and Figure 10, a relation between the mass flux and the density gradient for each material studied is shown. This function is quasi-linear for each slice considered. What approaches us to Fick's law which states that in a 


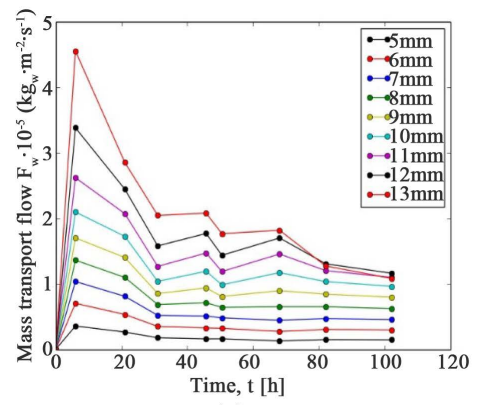

(a)

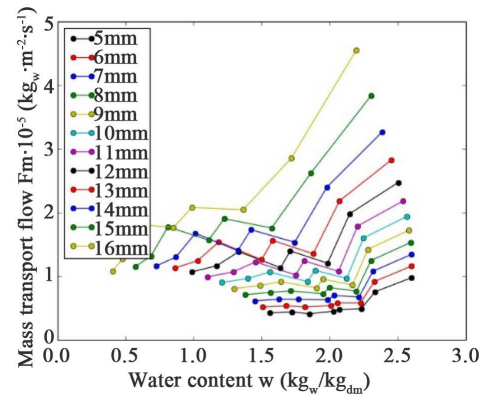

(c)

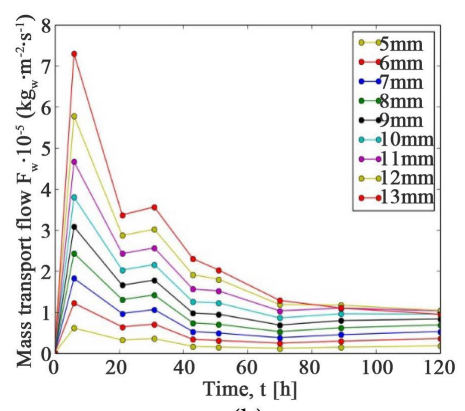

(b)

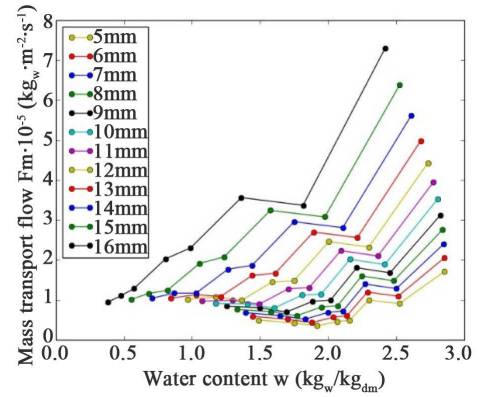

(d)

Figure 7. (a) Variation of the water flow in sample-B in function of time for various abscissas at $50^{\circ} \mathrm{C}$; (b) Variation of the water flow in sample- $\mathrm{F}$ in function of time for various abscissas at $50^{\circ} \mathrm{C}$; (c) Variation of the water flow in sample-B in function of the water content for various abscissas at $50^{\circ} \mathrm{C}$; (d) Variation of the water flow in sample-F in function of the water content for various abscissas at $50^{\circ} \mathrm{C}$.

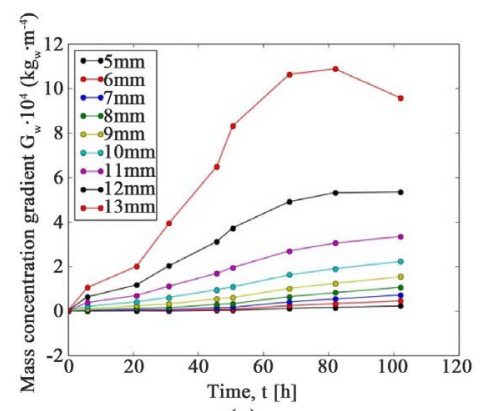

(a)

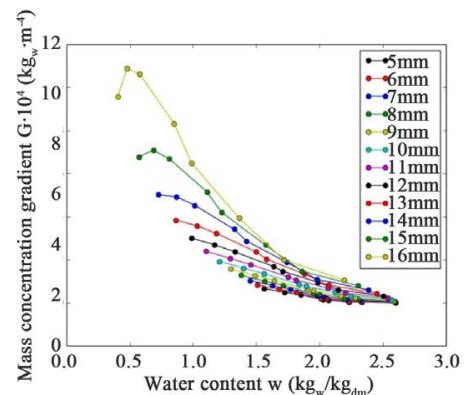

(c)

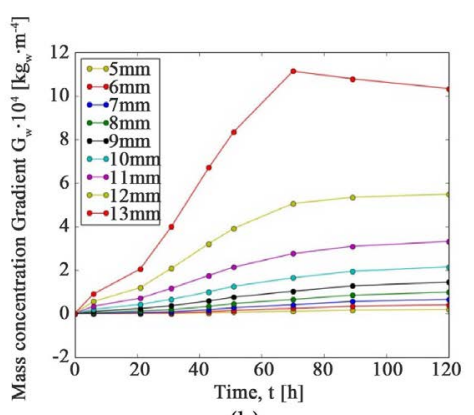

(b)

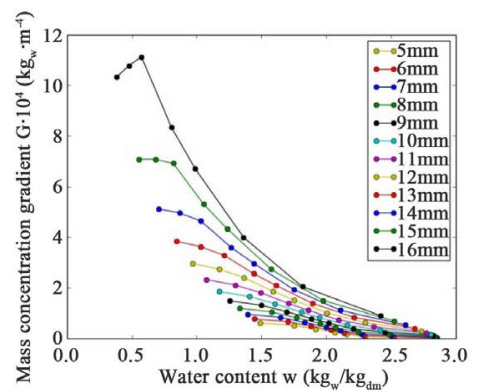

(d)

Figure 8. (a) Water concentration gradient of the sample-B in function of time for various abscissas at $50^{\circ} \mathrm{C}$; (b) Water concentration gradient of the sample-F in function of time for various abscissas at $50^{\circ} \mathrm{C}$; (c) Water concentration gradient in sample-B depending of the water content for various abscissas at $50^{\circ} \mathrm{C}$; (d) Water concentration gradient in sample-F depending of the water content for various abscissas at $50^{\circ} \mathrm{C}$. 


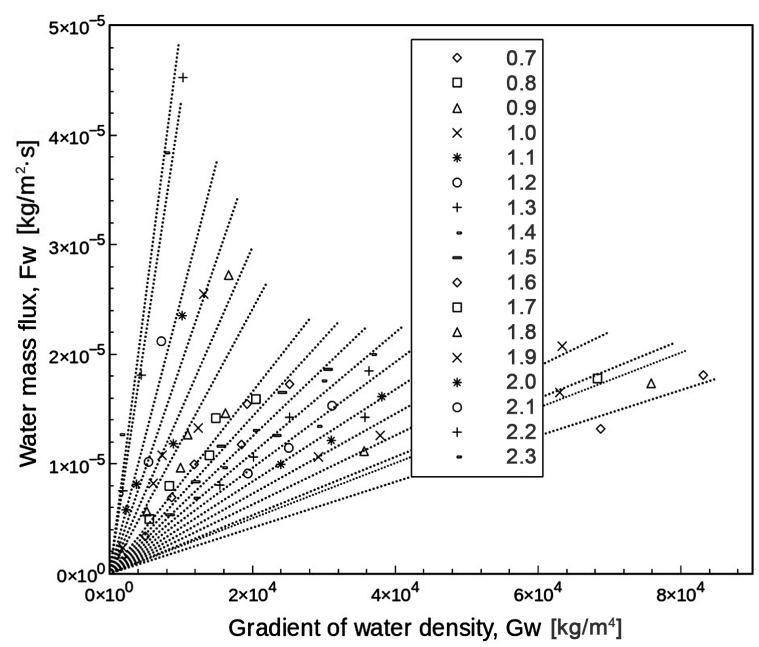

Figure 9. Water flow depending of the water concentration gradient in sample-B at $50^{\circ} \mathrm{C}$.

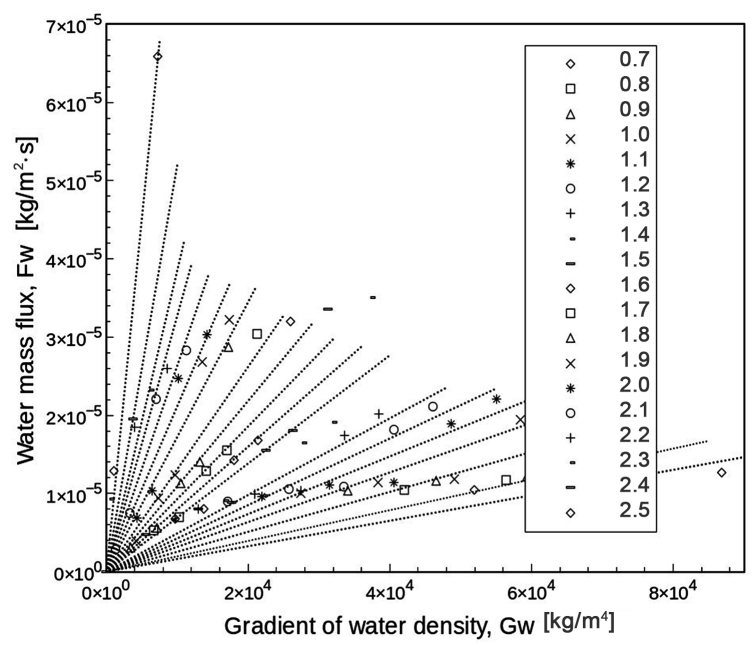

Figure 10. Water flow depending of the water concentration gradient in sample- $F$ at $50^{\circ} \mathrm{C}$.

homogeneous medium, the flow of the liquid phase can be described by a linear relation (Equation (13)).

\subsection{Water Transport Coefficient}

From the water content profiles, density gradients and fluxes presented above, the range of water content that can be studied is $0.7<w_{w}<2.5 \mathrm{~kg}_{\mathrm{w}} / \mathrm{kg}_{\mathrm{dm}}$. That is, from a horizontal line intersecting at least two water content profiles. In this range, the water flow and the apparent density gradient of water are determined by Equations (11) and (12). For each water content value, a relatively linear correlation is observed between the water flow and the gradient. Therefore, the water transport coefficient is determined from the slope of each linear approximation. For both strains (sample-B and sample-F), the dependencies of the water transport coefficients with respect to the water content are presented in Figure 11. It is noted that the experimental results are practically concordant. We can 


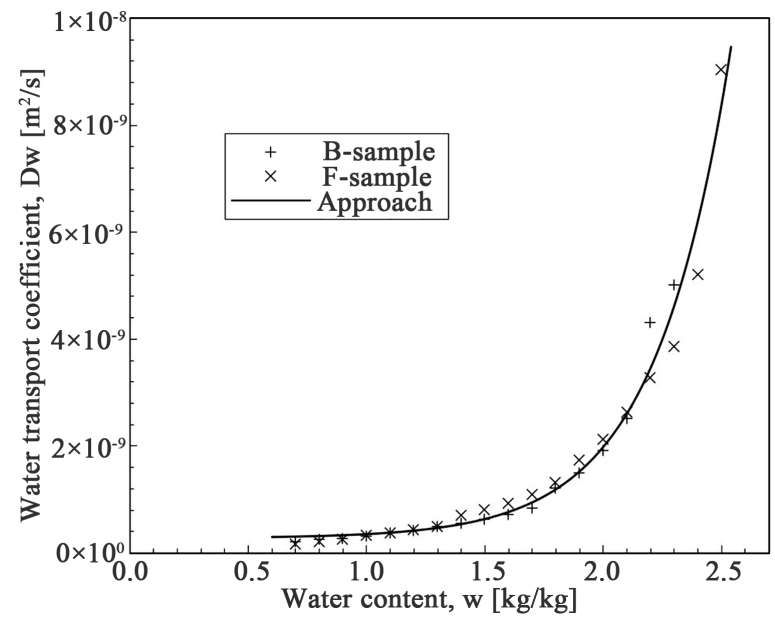

Figure 11. Water transport coefficient depending of the water content at $50^{\circ} \mathrm{C}$ : comparison of the experimental results and those of the model.

therefore consider that the two results are representative of a single evolution of the water transport coefficient of Spirulina type platensis. Experimental data are accurately described by an exponential equation (Equation (17)).

$$
D_{w}(w)=2.78 \times 10^{-10}+3.33 \times 10^{-12} \exp (3.12 w)
$$

An optimization algorithm based on a nonlinear regression procedure made it possible to obtain a good correlation between the experimental data and those of the theory with a correlation coefficient $R^{2}>97 \%$ and a standard deviation $R M S E<1.16 \times 10^{-10} \mathrm{~m}^{2} \cdot \mathrm{s}^{-1}$.

There is a sharp decrease in the transport coefficient for water contents above $2 \mathrm{~kg}_{\mathrm{w}} / \mathrm{kg}_{\mathrm{dm}}$ and a low decrease for low water contents. This trend has already been observed with rubber [30], agar gel [31] [32], clay [33], coffee [34] and wood [35]. $W=2 \mathrm{~kg}_{\mathrm{w}} / \mathrm{kg}_{\mathrm{dm}}$ represents a critical mean value from which the contribution of solid shrinkage to water transport is negligible. In the case of Spiruline platenis, previous work [36] [37] has shown that the solid acquires a mechanical strength and becomes progressively rigid during the last stages of drying. It should be remembered that the proposed destructive method satisfactorily assesses the water transport coefficient of Spirulina platensis over a wide range of water content.

\section{Conclusions}

This work enabled us to experimentally establish water content profiles during the one-dimensional drying process of Spirulina platensis by cutting samples. These profiles are then used to determine the influence of the water content on the mass flow, the water density gradient and the water transport coefficient that governs the internal phenomena. The distribution of water in the biomass is evaluated with the inclusion of the shrinkage along the cylindrical axis. The determined drying kinetics have similar profiles either in Sample-B or in Sample-F. It is shown that the proposed destructive method satisfactorily evaluates 
the evolution of the water content of Spirulina platensis over a wide range of water content.

The work carried out therefore provides a prospective tool that may be of interest for the local analysis of the water transport coefficient in other deformable materials. The development of a numerical model is necessary to compare the results and to predict the internal mechanisms during drying.

\section{Conflicts of Interest}

The authors declare no conflicts of interest regarding the publication of this pap.

\section{References}

[1] Bouraout, M., Richard, P. and Durance, T. (1994) Microwave and Convective Drying of Potato Slices. Journal of Food Process Engineering, 17, 353-363. https://doi.org/10.1111/j.1745-4530.1994.tb00343.x

[2] Yongsawatdigul, J. and Gunasekaran, S. (1996) Microwave Vaccum Drying of Cranberries Part II. Journal of Food Processing and Preservation, 20, 145-156. https://doi.org/10.1111/j.1745-4549.1996.tb00851.x

[3] Feng, H. and Tang, J. (1998) Microwave Finish Drying of Diced Apples in a Spouted Bed. Journal of Food Science, 63, 679-683. https://doi.org/10.1111/j.1365-2621.1998.tb15811.x

[4] Yang, F., Zhang, M., Mujumdar, A.S., Zhong, Q. and Wang, Z. (2018) Enhancing Drying Efficiency and Product Quality Using Advanced Pretreatments and Analytical Tools: An Overview. Drying Technology, 36, 1824-1838. https://doi.org/10.1080/07373937.2018.1431658

[5] Feng, Y., Zhang, M., Fan, K. and Mujumdar, A.S. (2018) Effects of Drying Methods on Quality of Fermented Plant Extract Powder. Drying Technology, 36, 1913-1919. https://doi.org/10.1080/07373937.2018.1461649

[6] Hiep Le, K., Hampel, N., Kharaghani, A., Bück, A. and Tsotsas, E. (2018) Superheated Steam Drying of Single Wood Particles: A Characteristic Drying Curve Model Deduced from Continuum Model Simulations and Assessed by Experiments. Drying Technology, 36, 1866-1881. https://doi.org/10.1080/07373937.2018.1444633

[7] R1etz, S., Porley, V.E., von Gersdorff, G., Hensel, O., Crichton, S. and Sturm, B. (2017) Effect of Maturation and Freezing on Quality and Drying Kinetics of Beef. Drying Technology, 35, 2002-2014. https://doi.org/10.1080/07373937.2017.1295051

[8] Tham, T.C., Ng, M.X., Gan, S.H., Chua, L.S., Aziz, R., Chuah, L.A., Hii, C.L., Ong, S.P., Chin, N.L. and Law, C.L. (2017) Effect of Ambient Conditions on Drying of Herbs in Solar Greenhouse Dryer with Integrated Heat Pump. Drying Technology, 35, 1721-1732. https://doi.org/10.1080/07373937.2016.1271984

[9] Börnhorst, M., Walzel, P., Rahimi, A., Kharaghani, A., Tsotsas, E., Nestle, N., Besser, A., Jäger, F.K. and Metzger, T. (2016) Influence of Pore Structure and Impregnation-Drying Conditions on the Solid Distribution in Porous Support Materials. Drying Technology, 34, 1964-1978.

https://doi.org/10.1080/07373937.2016.1147048

[10] Tsuruta, T., Tanigawa, H. and Sashi, H. (2015) Study on Shrinkage Deformation of Food in Microwave-Vacuum Drying. Drying Technology, 33, 1830-1836.

https://doi.org/10.1080/07373937.2015.1036286

[11] Miri Tari, S.M., Habibzade, S. and Taghiyari, H.R. (2015) Effects of Drying 
Schedules on Physical and Mechanical Properties in Paulownia Wood. Drying Technology, 33, 1981-1990. https://doi.org/10.1080/07373937.2014.948553

[12] Bénet, J.-C., Ramirez-Martinez, A., Ouedraogo, F. and Cherblanc, F. (2012) Measurement of the Chemichal Potential of a Liquid in Porous Media. Journal of Porous Media, 15, 1019-1029. https://doi.org/10.1615/JPorMedia.v15.i11.30

[13] Henrikson, R. (2000) Earthfood Spirulina. Earthrise, Ronore Enterprises.

[14] Maskan, M. (2001) Kinetics of Colour Change of Kiwifruits during Hot Air and Microwave Drying. Journal of Food Engineering, 48, 169-175. https://doi.org/10.1016/S0260-8774(00)00154-0

[15] Gowen, A.A., Abu-Ghannam, N., Frias, J. and Oliveira, J. (2008) Modeling Dehydratation and Rehydratation of Cooked Soybeans Subjected to Combined Microwave-Hot-Air Drying. Innovative Food Science and Emerging Technologies, 9, 129-137. https://doi.org/10.1016/j.ifset.2007.06.009

[16] Bourassa, J., Ramachandran, R.P., Paliwal, J. and Cenkowski, S. (2015) Drying Characteristics and Moisture Diffusivity of Distillers' Spent Grains Dried in Superheated Steam. Drying Technology, 33, 2012-2018. https://doi.org/10.1080/07373937.2015.1040883

[17] Compaore, A., Dissa, A.O., Rogaume, Y., Putranto, A., Chen, X.-D., Mangindaan, D., Zoulalian, A., Rémond, R. and Tiendrebeogo, E. (2016) Application of the Reaction Engineering Approach (REA) for Modeling of the Convective Drying of Onion. Drying Technology, 35, 500-508. https://doi.org/10.1080/07373937.2016.1192189

[18] Tsarahevitra, J., Loc, C. and Marie-Jose, L. (2004) Adaptation des souches de spiruline du sud de madagascar à la culture en eau de mer. In: Colloque international sur les cyanobactéries pour la santé, la science et le développement, Ile des Embiez.

[19] Enzing, C., Ploeg, M., Barbosa, M. and Sijtsma, L. (2014) Microalgae Based Products for the Food and Feed Sector: An Outlook for Europe. IPTS Institute for Prospective Technological Studies, JRC.

[20] Dissa, A., Desmorieux, H., Savadogo, P., Segda, B.G. and Koulidiati, J. (2010) Shrinkage, Porosity and Density Behaviour during Convective Drying of Spirulina. Journal of Food Engineering, 97, 410-418. https://doi.org/10.1016/j.jfoodeng.2009.10.036

[21] Bonazzi, C., Dumoulin, E. and Bimbenet, J.-J. (2008) Le séchage des produits alimentaires. Industrie Alimentaire Agricole, 125, 12-22.

[22] Desmorieux, H. and Hernandez, F. (2004). Biochemical and Physical Criteria of Spirulina after Different Drying Processes. In: Proceedings of the 14th International Drying Symposium (IDS 2004), Sào Paulo, Brazil.

[23] Desmorieux, H. and Decaen, N. (2005) Convective Drying of Spirulina in Thin Layer. Journal of Food Engenering, 66, 497-503. https://doi.org/10.1016/j.jfoodeng.2004.04.021

[24] Tiendrebeogo, E.S., Dissa, A.O., Cherblanc, F., Youm, I., Bénet, J.-C., Compaoré, A. and Koulidiati, J. (2015) Characterization of Two Different Stumps of Spirulina platensis Drying: Assessment of Water Transport Coefficient. Food and Nutrition Sciences, 6, 1437-1449. https://doi.org/10.4236/fns.2015.615148

[25] Mihoubi, D., Zagrouba, F., Vaxelaire, J., Bellagi, A. and Roques, M. (2004) Transfer Phenomena during the Drying of a Shrinkable Product, Modeling and Simulation. Drying Technology, 22, 91-109. https://doi.org/10.1081/DRT-120028216

[26] Hawladsr, M., Ho, J. and Qing, Z. (1999) A Mathematical Model for Drying of 
Shrinking Materials. Drying Technology, 17, 27-47. https://doi.org/10.1080/07373939908917517

[27] Couture, F., Laurent, S. and Roques, M.A. (2007) Drying of Two-Phase Media: Simulation with Liquid Pressure as Driven Force. AIChE Journal, 53, 1703-1717. https://doi.org/10.1002/aic.11213

[28] Crank, J. (1975) The Mathematics of Diffusion. Oxford University Press, London.

[29] Chemkhi, S., Zagrouba, F. and Bellagi, A. (2004) Mathematical Model for Drying of Highly Shrinkable Media. Drying Technology, 22, 1023-1039. https://doi.org/10.1081/DRT-120038578

[30] Auria, R. and Bénet, J.-C. (1990) Transport de l'eau dans une feuille de caoutchouc naturel pendant la période de séchage à vitesse décroissante. International Journal of Heat and Mass Transfer, 33, 1885-1894. https://doi.org/10.1016/0017-9310(90)90220-O

[31] Mrani, I., Bénet, J. and Fras, G. (1995) Transport of Water in a Biconstituent Elastic Medium. Applied Mechanics Review, 48, 717-721. https://doi.org/10.1115/1.3005053

[32] Mrani, I. (1993) Transport de matière en milieu biconstituant élastique: application au séchage du gel d'agar. Ph.D. Thesis, Université Montpellier, Montpellier, France.

[33] Ketelaars, A., Pel, L., Coumans, W. and Kerkhof, P. (1995) Drying Kinetics: A Comparison of Diffusion Coefficients from Moisture Concentration Profiles and Drying Curves. Chemical Enaineerir Science, 50, 1187-1191. https://doi.org/10.1016/0009-2509(94)00494-C

[34] Ramirez-Martinez, A., Salgado-Cervantes, M., Rodriguez-Jimenes, G., Garcia-Alvarado, M., Cherblanc, F. and Bénet, J.-C. (2013) Water Transport in Parchment and Endosperm of Coffee Bean. Journal of Food Engineering, 114, 375-383. https://doi.org/10.1016/j.jfoodeng.2012.08.028

[35] Anoua, M., Ramirez-Martinez, A., Cherblanc, F. and Bénet, J.-C. (2014) The Use of Chemical Potential to Describe Water Transfer in Complex Media with Strong Solid-Liquid Bonding. Transport in Porous Media, 102, 111-122. https://doi.org/10.1007/s11242-013-0265-4

[36] Dissa, A., Compaore, A., Tiendrebeogo, E. and Koulidiati, J. (2014) An Effective Moisture Diffusivity Model Deduced from Experiment and Numerical Solution of Mass Transfer Equations for a Shrinkable Drying Slab of Microalgae Spirulina. Drying Technology, 32, 1231-1244. https://doi.org/10.1080/07373937.2014.897234

[37] Tiendrebeogo, S.E. and Dissa, A.O. (2015) Guy Christian Tubreoumya, Kayaba Haro, Fabien Cherblanc, J Koulidiati, Couplage des mécanismes de déshydratation et du retrait de la Spiruline platensis "Arthrospira platensis" lors d'un séchage isotherme. Journal de la Société Ouest-Africaine de Chimie, 040, 17-23. 


\section{Nomenclature}

RH: relative humidity (\%)

$d b$ : dry matter $\left(\mathrm{kg}_{\mathrm{w}} / \mathrm{kg}_{\mathrm{dm}}\right)$

$d:$ cylinder diameter

$w$. water content $(\mathrm{kg} / \mathrm{kg})$

$a_{w}$ : water activity $(/)$

$D_{w}$ : transport coefficient $\left(\mathrm{m}^{2} / \mathrm{s}\right)$

$F_{w}$ : mass water flux $\left(\mathrm{kg} \cdot \mathrm{m}^{-2} \cdot \mathrm{s}^{-1}\right)$

$G_{w}:$ gradient of water density $\left(\mathrm{kg} / \mathrm{m}^{4}\right)$

$m_{e q}$ : equilibrium mass of sample $(\mathrm{kg})$

$m_{i}$ : sample initial mass $(\mathrm{kg})$

$x$. sample thickness $(\mathrm{m})$

$m_{s}:$ dry mass of sample $(\mathrm{kg})$

$u_{s}$ : velocity of the solid phase $(\mathrm{m} / \mathrm{s})$

$u_{w}$ : velocity of the liquid phase $(\mathrm{m} / \mathrm{s})$

$N$ : number of observations

$R^{2}$ : correlation coefficient (\%)

RMSE: root mean square error $(\mathrm{kg} / \mathrm{kg})$

$w_{e q}$ : equilibrium moisture content $(\mathrm{kg} / \mathrm{kg})$

$Y$ : given drying parameter

$m(t)$ : sample mass at a instant $(\mathrm{kg})$

$Y_{\text {pre }, j}$ : the $i$ th predicted value of $Y$

$\bar{Y}_{\text {exp,j }}$ : mean experimental value of $Y$

$Y_{e x p, j}$ : given drying parameter $Y$

Greek Letters

$\alpha$ : real densities ratio $(/)$

$\rho_{s}:$ solid apparent density $\left(\mathrm{kg} / \mathrm{m}^{3}\right)$

$\rho_{w}$ : water apparent density $\left(\mathrm{kg} / \mathrm{m}^{3}\right)$

$\rho_{s}^{*}$ : solid real density $\left(\mathrm{kg} / \mathrm{m}^{3}\right)$

$\rho_{w}^{*}$ : water real density $\left(\mathrm{kg} / \mathrm{m}^{3}\right)$

$\phi$ : porosity (/)

\section{Subscripts}

0 : initial

$Z$ : number counter of parameters

$i, j$ : respectively abscissa and time counters

$w$, db: water, dry matter

eq: equilibrium

Exp: experimental

Pre: predicted

s. solid

1D: unidimensionnel 